\title{
Prevention Models of Childhood Obesity in Sweden
}

\author{
Carl-Erik Flodmark \\ Childhood Obesity Unit, Skåne University Hospital, Malmö, Sweden
}

\author{
Keywords \\ Prevention · Childhood obesity
}

\begin{abstract}
The impact of childhood obesity on the Swedish Health Care system is described. Childhood Obesity and Diabetes Type 2 is increasing for the last 10 years, but not Diabetes Type 1. Thus, prevention is needed. How to define prevention of obesity? Could treatment of childhood obesity be regarded as prevention of adult obesity? Of course it could, but we are lacking a long term follow-up from childhood to adulthood. However, we know that childhood obesity is a risk factor for adult disease. But we need long-lasting results in children to being able to state that we have prevented adult obesity. What about treatment of children with overweight, i.e. defined as the less severe level of an increased body weight as opposed to obesity? There are few if any studies restricting the treatment only to overweight children. Normally, obese children are treated, and some overweight children are added usually to increase the study sample. Then of course promotion of a healthy lifestyle could be of major interest. Finally, the traditional concept of primary prevention seems to be the only solution that is realistic according to many. However, there is no clear pattern when primary prevention works.

(c) 2018 The Author(s)

Published by S. Karger GmbH, Freiburg
\end{abstract}

\section{Introduction}

The numbers of children per 100,000 children diagnosed with childhood obesity in Sweden has increased 2- to 3-fold in 10 years (fig. 1). This is of course both an effect of the increase of childhood obesity in the society but also of the increasing possibilities and offers to treat these children. Normally, they are treated at pediatric clinics in Sweden, and these clinics are included in the statistics used that covers all hospitals in Sweden (www.social- 
Flodmark et al.: Prevention Models of Childhood Obesity in Sweden

Fig. 1. Data has been extracted from The Swedish National Patient Outpatient Register. Pediatric obesity at the pediatric departments or other hospital clinics is shown for the last 10 years per 100,000 children. There is a clear increase in the children diagnosed. Data is not available from general practitioners. See also www.socialstyrelsen.se/register/ halsodataregister/patientregistret/inenglish.

Fig. 2. Data has been extracted from The Swedish National Patient Outpatient Register. Diabetes type 2 at the pediatric departments or other hospital clinics is shown for the last 10 years per 100,000 children. There is an increase although the numbers are small. Data is not available from general practitioners. See also www.socialstyrelsen.se/register/ halsodataregister/patientregistret/inenglish.

Fig. 3. Data has been extracted from The Swedish National Patient Outpatient Register. Diabetes type 1 at the pediatric departments or other hospital clinics is shown for the last 10 years per 100,000 children. There is no significant increase. Data is not available from general practitioners. See also www.socialstyrelsen.se/ register/halsodataregister/patientregistret/inenglish.
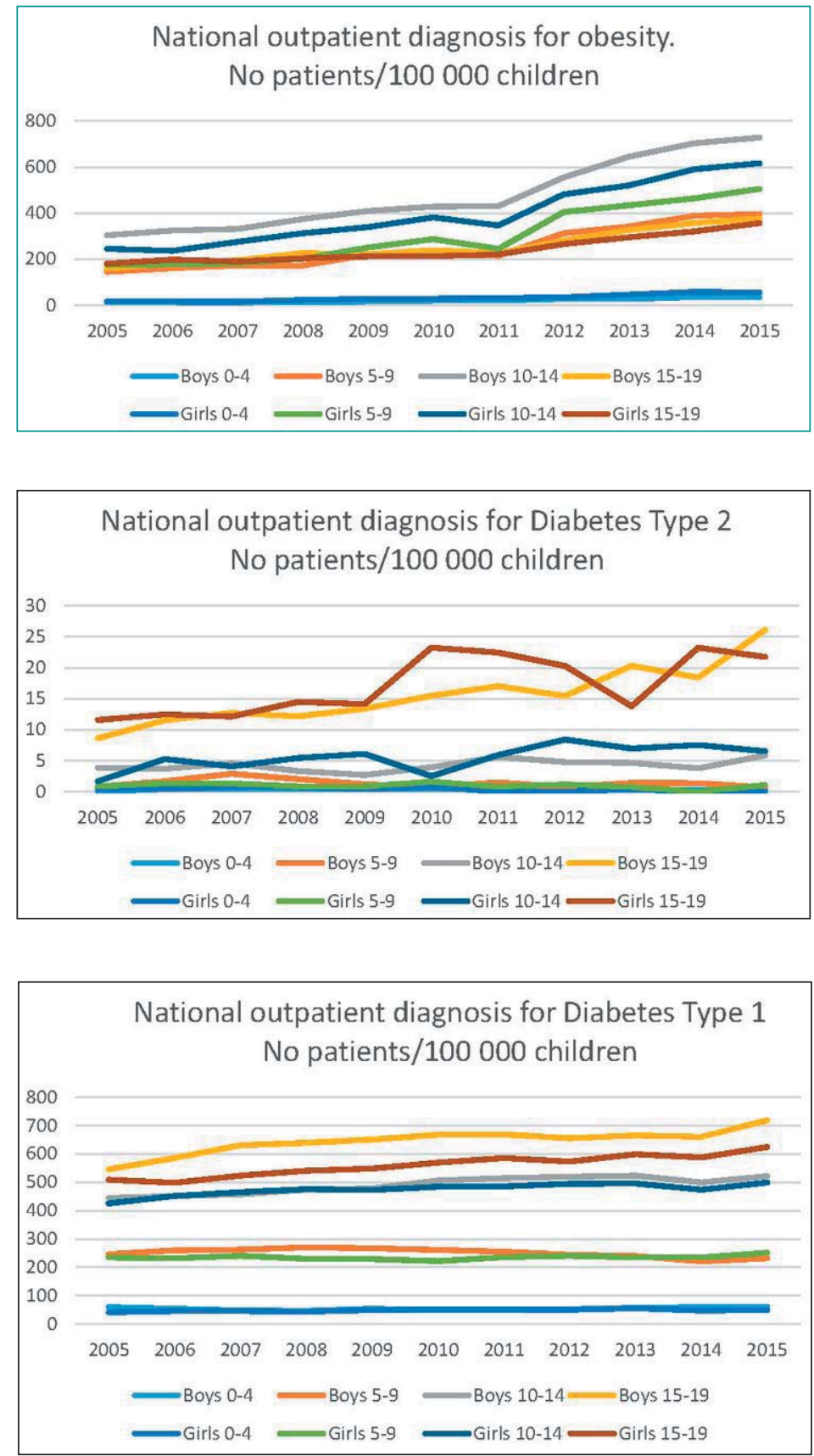

styrelsen.se/register/halsodataregister/patientregistret/inenglish). Data from primary care and general practitioners is not included. However, they rarely treat childhood obesity in Sweden.

Diabetes type 2 has increased 3 times in boys 15-19 years and almost 4 times in girls 10-14 years (fig. 2). However, the numbers are small, and there is an uncertainty regarding absolute numbers. This might still being connected to the increase in pediatric obesity in Sweden although a causal relationship cannot be established in these epidemiological data.

Regarding diabetes type 1, there is a small increase of 20-30\% for teenagers 15-19 years of age (fig. 3). This seems to be a much lower increase than in diabetes type 2 or obesity indicating that there is a true increase in diabetes type 2 in Sweden. 
These effects on the health care system of course makes it clear that prevention is of major interest, and there is no indication of a levelling off regarding the impact on the health care system of pediatric obesity in Sweden.

\section{Prevention Models of Childhood Obesity in Sweden}

How to define prevention of obesity? Could treatment of childhood obesity be regarded as prevention of adult obesity [1]? Of course it could, but we are lacking a long-term followup from childhood to adulthood. However, we know that childhood obesity is a risk factor for adult disease [2,3]. But we need long-lasting results in children to be able to state that we have prevented adult obesity. Surgical treatment might give a long-lasting result until adulthood [4].

What about treatment of children with overweight, i.e. defined as the less severe level of an increased body weight as opposed to obesity? There are few if any studies restricting the treatment only to overweight children. Normally obese children are treated, and some overweight children are added usually to increase the study sample [5].

Then of course promotion of a healthy lifestyle could be of major interest. This is so in Sweden as there is no action plan against childhood obesity. Instead there are several attempts to promote a healthy lifestyle. One of the most well-known is 79 steps as a background for an action plan for better food habits and increased physical activity by the Swedish Public Health Agency and the National Food Agency [6]. The steps were divided into different political areas in society, e.g.: goal no 55 was supposed to investigate the effects of taxation on foods preventing obesity. There was never a decision to implement an action plan, and no financial support was given. However, the discussion in public legal bodies inspired local initiatives, e.g., in the county of Malmö, where an action plan with specific goals was enacted.

Finally, the traditional concept of primary prevention seems to be the only solution that is realistic according to the expert group at the National Food Agency, Sweden [7]. The conclusion is further supported by a systematic review done by the Swedish Agency for Health Technology Assessment [8] showing that prevention of obesity is possible.

\section{National and Regional Guidelines}

In Sweden, the Swedish National Board of Health and Welfare issues 15 national guidelines. There are no guidelines on the treatment of obesity. Instead there are national guidelines promoting a healthy lifestyle by disease-preventing methods (under revision) [9]. Furthermore the Public Health Agency of Sweden has the assignment to promote physical activity, using among others tools the national guidelines mentioned above.

The 21 regional health care counties have in many instances also issued local guidelines on the treatment of obesity.

\section{Arenas of Prevention}

In Sweden, 98-99\% of all children attend the child health care between ages 0 until 6 years. Then the school health care service has a similar coverage due to the obligation to attend school. The health care system is still voluntary but has a good reputation and gives an important support to all families. The child health care and the school health care is a natural arena for detecting obesity as all children are measured regularly. Child health care is free of 
charge and uses a health care program that was developed by the professions responsible such as pediatricians, general practitioners, child nurses, and psychologists. Additional professionals are also supporting this service e.g. speech therapists, dental nurses, audiologists, and orthoptists, The children could be referred to specialized centers, or the specialists could visit the local child health care center giving health care in the local area. The school health care is also free of charge, and the health care program is developed by the professions. The specialized school nurse could be supported by additional pedagogical staff such as special teachers focusing on teaching methods. Furthermore, the nurses give also parental education, and this has been given attention recently [10].

However, in these arenas of prevention, there are no specialized therapists regarding obesity or overweight. There has been a common belief that the parental and child supporting system also could be used more systematically against obesity by adding special elements to the universal supporting program. The Swedish health care system is an example of a universal supporting system reaching the full population. This could also be used against obesity, and below some examples on research in this field is given.

\section{What Type of Treatment is Effective?}

Method fidelity is crucial in behavioral treatments, and the modifications made by professionals might be fidelity-consistent or fidelity-inconsistent [11]. If a fidelity-inconsistent change is made, the effect of the treatment might be influenced. In behavioral treatment for conduct disorders, the process to make evidence-based programs to spread and to guarantee quality is well-known in that field [12]. This is also necessary in the field of obesity when using behavioral treatment programs and could be one explanation that not all studies are successful although established treatments are used.

In a study from Sweden that has been presented at the European Obesity Summit in Gothenburg motivational interviewing (MI) was used as an intervention focusing on young children [13]. The study population consisted of 1,355 families with 1,369 infants that were given one group session and eight individual sessions during 39 months with a nurse trained in MI starting at an age of 10 months [13]. There was no effect on children's BMI, waist circumference, or prevalence of overweight and also no effect on mothers' anthropometric data or regarding mothers' and children's physical activity habits, but there was a small effect in terms of healthier food habits [13].

Thus, the supporting environment using child health care with added special techniques did not work. Was this due to lack of method fidelity?

'The More or Less Study' [14] used another technique developed by the Oregon Social Learning Center for giving family support. The recruitment has been finished, and the 4-year evaluation has been performed 2017. This randomized controlled trial included 65 families in parental support that were compared with 80 families giving usual care at a pediatric clinic [15]. If the results still are beneficial at 4 years, there is evidence that family support can help early in life.

However, in a previous study done within the Swedish child health care system prevention showed to be ineffective [16]. The Early StOPP (Stockholm Obesity Prevention Program) included 135 high-risk children aged 1-6 years (with 2 overweight parents or 1 obese parent). In this randomized controlled trial, 53 children were given the intervention, and 82 were in the control group. There was a significant effect after 1 year of intervention compared to baseline. However, there was no difference between the groups indicating that it is important to validate a method against a control group. It is not sufficient to conclude that an intervention has an effect if there only is a before and after effect. 
Furthermore, even if treatments works better for young children, we could not leave the teenagers alone. There are studies showing results also in teenagers using techniques based on family therapy and solution-focused treatment [17]. These programs are developed for treatment but they can also be used as adaptation giving prevention instead [18].

Family therapy programs are based on the family's needs and strengths, and this gives an adaptation automatically to gender and socioeconomic status. Thus, in such programs there is no need for designing specific procedures for different groups as the program itself gives an adaptation to the specific needs of the identified patient and the closest environment, i.e., the patient's family. The heritability in obesity is high (0.3-0.6), but the effect of shared environment seems to diminish by age leaving effects of the non-shared environment. As we cannot change the genes, we have two options to work with the shared environment: addressing the family and/or to work with the non-shared environment, e.g. socioeconomic factors including areas with poor quality of dwelling. Thus, school-based programs related to areas of different types of dwellings should be considered as the teenagers spend a considerable amount of time at school that should be an appropriate area of prevention and treatment.

To conclude, what is left would be much more research for such a common disease.

\section{Disclosure Statement}

No conflict of interest given.

\section{References}

1 Flodmark CE, Ohlsson T, Ryden O, Sveger T: Prevention of progression to severe obesity in a group of obese schoolchildren treated with family therapy. Pediatrics 1993;91:880-884.

2 Mossberg HO: 40-year follow-up of overweight children. Lancet 1989;2:491-493.

3 Must A, Jacques PF, Dallal GE, Bajema CJ, Dietz WH: Long-term morbidity and mortality of overweight adolescents. A follow-up of the Harvard Growth Study of 1922 to 1935. N Engl J Med 1992;327:1350-1355.

-4 Olbers T, Beamish AJ, Gronowitz E, Flodmark CE, Dahlgren J, Bruze G, Ekbom K, Friberg P, Gothberg G, Jarvholm K, Karlsson J, Marild S, Neovius M, Peltonen M, Marcus C: Laparoscopic Roux-en-Y gastric bypass in adolescents with severe obesity (AMOS): a prospective, 5-year, Swedish nationwide study. Lancet Diabetes Endocrinol 2017;5:174-183.

5okkvoll AS: Reversing childhood obesity. Acta Paediatr 2016;105:1191.

6 National Food Agency: Background for an action plan for better food habits and increased physical activity. 2003 (in Swedish). www.livsmedelsverket.se/globalassets/rapporter/2005/underlag_handlingsplan_ slutappport.pdf (last accessed June 11, 2018).

7 Perlhagen J, Flodmark CE, Hernell 0: Obesity in children - prevention is the only realistic solution of the problem (in Swedish). Lakartidningen 2007;104:138-141.

-8 Flodmark CE, Marcus C, Britton M: Interventions to prevent obesity in children and adolescents: a systematic literature review. Int J Obes (Lond) 2006;30:579-589.

9 National Board of Health and Welfare: National guideline for disease-preventing methods. 2017. www.socialstyrelsen.se/psidata/nationellariktlinjerforsjukdom (last accessed June 11, 2018).

$\rightarrow 10$ Lefevre A, Lundqvist P, Drevenhorn E, Hallstrom I: Parents' experiences of parental groups in Swedish child health-care: Do they get what they want? J Child Health Care 2016;20:46-54.

11 Wiltsey Stirman S, Gutner CA, Crits-Christoph P, Edmunds J, Evans AC, Beidas RS, A Gutner C: Relationships between clinician-level attributes and fidelity-consistent and fidelity-inconsistent modifications to an evidence-based psychotherapy. Implement Sci 2015;10:115.

$\rightarrow 12$ Henggeler SW, Sheidow AJ: Empirically supported family-based treatments for conduct disorder and delinquency in adolescents. J Marital Fam Ther 2012;38:30-58.

13 Döring N, Ghaderi A, Bohman B, Heitman B, Larsson C, Berglind D, Hansson L, Sundblomd E, Magnusson M, Blennow M, Tynelius P, Forsberg L, Rasmussen F: Primary prevention of childhood obesity within child health services: The PRIMROSE cluster RCT. Obes Facts 2016;9(suppl 1):35.

14 Ek A, Chamberlain KL, Ejderhamn J, Fisher PA, Marcus C, Chamberlain P, Nowicka P: The More and Less Study: a randomized controlled trial testing different approaches to treat obesity in preschoolers. BMC Public Health 2015;15:735. 
Flodmark et al.: Prevention Models of Childhood Obesity in Sweden

15 Ek A: The more or less study. 2017: Scientific web report (in Swedish). http://ki.se/clintec/meroch-mindre-studien-mom (last accessed June 11, 2018).

16 Svensson V, Johansson E, Ek A, Forssen M, Ekbom K, Nowicka P, Ekstedt M, Hagströmer M, Marcus C: Effects of one year obesity prevention on relative weight and dietary intake in toddlers with overweight or obese parents. Early STOPP, a randomized controlled intervention. Appetite 2015;2015:303.

17 Nowicka P, Pietrobelli A, Flodmark CE: Low-intensity family therapy intervention is useful in a clinical setting to treat obese and extremely obese children. Int J Pediatr Obes 2007;2:211-217.

$\checkmark 18$ Nowicka P, Hoglund P, Pietrobelli A, Lissau I, Flodmark CE: Family Weight School treatment: 1-year results in obese adolescents. Int J Pediatr Obes 2008;3:141-147. 